\title{
The sodium pump controls the frequency of action-potential-induced calcium oscillations
}

\author{
SHIVENDRA G. TEWARI* \\ Systems Science and Informatics Unit, Indian Statistical Institute, \\ $8^{\text {th }}$ Mile, Mysore Road, Bangalore 560059, India \\ E-mail: tewarisg@gmail.com
}

\begin{abstract}
Calcium plays a significant role in a number of cellular processes, like muscle contraction, gene expression, synaptic plasticity, signal transduction, but the significance of calcium oscillations ( $\mathrm{CaOs})$ is not yet completely understood in most of the cell types. It is a widely accepted fact that $\mathrm{CaO}$ s are a frequency encoded signal that allows a cell to use calcium as a second messenger while avoiding its toxic effects. These intracellular $\mathrm{CaOs}$ are primarily driven by some agonist-dependent pathways or fluctuations in membrane potential. The present mathematical model is of the latter type. The model incorporates expression for all major intracellular ionic species and membrane proteins. Especially, it integrates the coupling effect of sodium pump and $\mathrm{Na}^{+} / \mathrm{Ca}^{2+}$ exchanger over CaOs. By varying sodium pump current, it is found that, sodium pump is a key player in modulating intracellular CaOs. The model predicts that the sodium pump can play a decisive role in regulating intercellular cell signaling process. The present study forms the basis for sodium pump controlled intercellular signaling process and requires further experimental verification.
\end{abstract}

Mathematical subject classification: $34 \mathrm{M} 10,92 \mathrm{C} 20$.

Key words: $\mathrm{Na}^{+} / \mathrm{Ca}^{2+}$ exchanger, sodium pump, calcium oscillations, membrane potential.

\section{Introduction}

A number of investigators have performed experiments to study the behavior of cytosolic calcium $\left(\mathrm{Ca}^{2+}\right)$ and the parameters affecting its behavior [1, 2, 3].

\#CAM-365/11. Received: 02/V/11. Accepted: 11/IX/11.

*Present address: Biotechnology \& Bioengineering Center, and Department of Physiology, Medical College of Wisconsin, 8701 Watertown Plank Road, Milwaukee, WI 53226, USA. 
But till date the function of cytosolic Calcium oscillations ( $\mathrm{CaOs}$ ) has not been completely understood in most cell types. CaOs are known to play a key role in a number of mechanisms like activation of extracellular signal regulated kinase (ERK) $[4,5]$, the contraction of smooth muscle [6], increase in the frequency of synaptic currents [7] and maturation of Xenopus laevis Oocyte [8]. These $\mathrm{CaOs}$ are supposed to contain frequency-encoded signals that help in using $\mathrm{Ca}^{2+}$ as a second messenger while avoiding its high intracellular concentrations [9]. Also, in the process of signal transduction, intracellular $\mathrm{Ca}^{2+}$ behaves like a switch and decides whether a particular signal needs to be further propagated or not. The increase in intracellular concentration is facilitated by the opening of transmembrane $\mathrm{Ca}^{2+}$ channels which lead to the opening of channels at the intracellular stores. There are mainly Rynodine Receptors (RyRs) or Inositol Triphosphate Receptors ( $\left.\mathrm{IP}_{3} \mathrm{Rs}\right)$ that are located at the membrane of endoplasmic reticulum (in neurons) or sarcoplasmic reticulum (in myocytes) which causes an efflux of $\mathrm{Ca}^{2+}$ from the intracellular stores. The release of $\mathrm{Ca}^{2+}$ through $\mathrm{IP}_{3} \mathrm{Rs}$ is as a result of some agonist or neurotransmitter binding to its receptor which can cause via G-protein link to phospholipase C (PLC), the cleavage of phosphotidylinositol $(4,5)$-bisphosphate $\left(\mathrm{PIP}_{2}\right)$ to inositol triphosphate $\left(\mathrm{IP}_{3}\right)$ and diacylglycerol (DAG). This released $\mathrm{IP}_{3}$ is free to diffuse through the cytosol and binds with $\mathrm{IP}_{3} \mathrm{R}$ and leading to the subsequent opening of these receptors and release of $\mathrm{Ca}^{2+}$ from the intracellular stores. $\mathrm{CaOs}$ can be classified into mainly two types:

1) that is induced by changing membrane potential as in the case of an action potential; and

2) that occur in the presence of voltage clamp. The latter part can be further categorized based on the fact that the oscillatory $\mathrm{Ca}^{2+}$ flux is from RyRs or $\mathrm{IP}_{3} \mathrm{Rs}$ but our focus is on the first type.

Jafri et al. [6] showed $\mathrm{CaOs}$ for changing membrane potential of endoplasmic reticulum (ER), Atri et al. [10] showed $\mathrm{CaOs}$ for $\mathrm{Ca}^{2+}$ flux through the $\mathrm{IP}_{3} \mathrm{Rs}$ in Xenopus laevis Oocyte and determined the intermediate range of $\mathrm{IP}_{3}$ for CaOs. Wagner and Keizer [11] showed the effect of rapid buffering over CaOs. Later on, Kusters et al. [12] proposed an integrated model which combines excitable membrane with an $\mathrm{IP}_{3}$ mediated $\mathrm{Ca}^{2+}$ oscillator for normal rat 
kidney (NRK) fibroblast. Recently, Silva et al. [13] proposed a mathematical model for endothelial cells which incorporated nearly all the important biophysical parameters but is unable to exhibit CaOs. Thus, we can say that in all the investigations on $\mathrm{CaOs}$ carried out by researchers so far, none of the investigators have tried to incorporate the effect of changing cytosolic $\mathrm{Na}^{+}$and $\mathrm{K}^{+}$ions over $\mathrm{CaOs}$. Thus, in this article, we have proposed a mathematical model governing $\mathrm{CaOs}$ for changing membrane potential in the absence of fluxes from the intracellular stores. Holmgren et al. [14] determined the three distinct steps of $\mathrm{Na}^{+}$ ion release from the sodium pump with the help of high speed voltage jumps. Here, we have tried to incorporate the impact of these distinct steps of sodium pump over cytosolic $\mathrm{CaOs}$, in case of an action potential. Thus, we have incorporated L-type $\mathrm{Ca}^{2+}$ channel, $\mathrm{Na}^{+}$channel, $\mathrm{K}^{+}$channel, Plasma-Membrane (PM) $\mathrm{Ca}^{2+}$ ATPase, $\mathrm{Na}^{+} / \mathrm{Ca}^{2+}$ exchanger (NCX), $\mathrm{Na}^{+} / \mathrm{K}^{+}$ATPase (Sodium pump), inward rectifier potassium channel $\left(\mathrm{K}_{i r}\right), \mathrm{Ca}^{2+}$ dependent intermediate potassium channel $\left(\mathrm{IK}_{\mathrm{Ca}}, \mathrm{Ca}^{2+}\right.$ dependent small potassium channel $\left(\mathrm{SK}_{\mathrm{Ca}}\right)$ and dynamic membrane potential. The gating mechanism of the trasmembrane channels emulate the gating mechanism of the famous Hodgkin and Huxley model [15]. Further, the pumps and proteins are modeled to have realistic gating mechanism such that they are in agreement with the biological facts. The proposed mathematical model leads to a system of non-linear ordinary differential equations. We have used Euler's method for the simulation of the proposed model for which a MATLAB script has been written.

\section{Mathematical formulation}

Our cell model assumes that cell is cylindrical in shape. The diameter of cell is assumed to be $20 \mu \mathrm{m}$ and its length to be $100 \mu \mathrm{m}$ (see Fig. 1). Its specific membrane capacitance is taken to be $1 \mu \mathrm{F} / \mathrm{cm}^{2}$. As mentioned in literature $[16,17,18]$, we have taken actual surface area $\left(\mathrm{A}_{\text {cap }}\right)$ of cell to be larger than its geometrical surface area. Further, the channels, proteins and pumps are supposed to be homogenously distributed throughout the membrane. The formulation of the proposed mathematical model comprises of different components which are elaborated in the following subsections: 


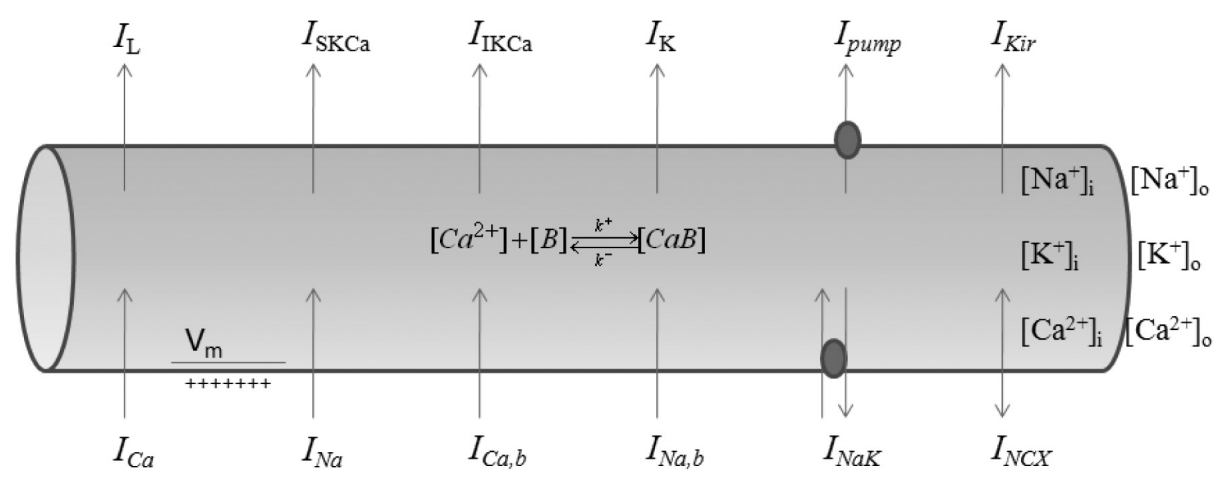

Figure 1 - Schematic diagram of the cell model. The abbreviations representing ionic concentrations, currents, pumps, proteins and exchangers are defined in this section.

\subsection{The $\mathrm{Ca}^{2+}$ channel}

The L-type $\mathrm{Ca}^{2+}$ channel is supposed to have a permeability ratio of 36000:1:18 for $\mathrm{Ca}^{2+}, \mathrm{Na}^{+}$and $\mathrm{K}^{+}$ions, respectively [19]. The voltage gated $\mathrm{Ca}^{2+}$ channel was modeled using non-linear Goldman-Hodgkin-Katz (GHK) current equation $[9,20]$, which can be stated as,

$$
I_{S, L}=P_{S} z_{S}^{2} \frac{F^{2} V_{m}}{R T} \frac{\gamma_{i}\left[S_{i}\right]-\gamma_{o}\left[S_{o}\right] \exp \left(-\frac{z_{s} F V_{m}}{R T}\right)}{1-\exp \left(-\frac{z_{s} F V_{m}}{R T}\right)}
$$

where, $S$ is any of the ions, $[S]_{i}$ and $[S]_{o}$ are the intracellular and extracellular concentration of $S$ ion respectively (in $\mathrm{mM}$ ), $P_{S}$ is permeability (in $\mathrm{cm} / \mathrm{s}$ ) of $S$ ion, $z_{S}$ is its valence, $\gamma_{i}, \gamma_{o}$ are the activity coefficient (a.c.) of the $S$ ion, $F$ is Faradays constant (in Coulombs/moles), $V_{m}$ is membrane potential (in volts), $R$ is real gas constant (in $\mathrm{J} / \mathrm{K}$ moles) and $T$ is absolute temperature (in $\mathrm{K}$ ). The total current through the L-type $\mathrm{Ca}^{2+}$ channel is

$$
I_{C a, t}=I_{C a, L}+I_{N a, L}+I_{K, L} .
$$

Further, equation (1) is converted into fluxes (in $\mathrm{mM} / \mathrm{second}$ ), before being used as an expression for individual ionic concentrations, by using Faraday's constant, Volume of the cytosol $\left(V_{c y t}\right)$ and using the fact that $1 \mathrm{~L}=10^{-3} \mathrm{~m}^{3}$,

$$
\sigma_{S, L}=-\frac{I_{S} A_{c a p}}{z_{S} F V_{c y t}}
$$


where, $S$ is any of the ion and $L$ signifies $L$-type $\mathrm{Ca}^{2+}$ channel. In equation (2) there is a negative sign against it because by convention inward current is taken to be negative.

\section{2 $\mathrm{PMCa}^{2+}$ ATPase}

$\mathrm{PM} \mathrm{Ca}^{2+}$ ATPase (PMCA) is a P-type ATPase. The energy required to extrude $\mathrm{Ca}^{2+}$ out of the cytosol is met by ATP. The kinetics of this pump follows the enzyme-substrate formulism and hence using Michaelis Menten type kinetics [21], one can formulate the net efflux of $\mathrm{Ca}^{2+}$ ions out of the cytosol by,

$$
\sigma_{\text {pump }}=-\frac{\hat{I}_{\text {pump }} A_{c a p}}{z_{C a} F V_{c y t}}
$$

where, $\hat{I}_{\text {pump }}$ is the pump current given by the following equation,

$$
\hat{I}_{\text {pump }}=I_{\text {pump }} \frac{\left[C a^{2+}\right]^{H, p u m p}}{\left[C a^{2+}\right]^{H, p u m p}+K_{m}^{H, p u m p}}
$$

where, $\left[\mathrm{Ca}^{2+}\right]$ is the intracellular $\mathrm{Ca}^{2+}$ concentraton (in $\mathrm{mM}$ ), H, pump is the Hill's coefficient for PMCA, $K_{m}^{H, \text { pump }}$ is the $\mathrm{Ca}^{2+}$ concentration at which the maximum pump current is halved (in $\mathrm{mM}$ ).

\section{$2.3 \mathrm{Na}^{+} / \mathrm{Ca}^{2+}$ exchanger}

This protein is known to play an important role in excitation-contraction coupling in cardiac myocytes [22]. In neurons this protein helps in the extrusion of cytosolic $\mathrm{Ca}^{2+}$ concentration and hence helps in the modulation of neurotransmitter release [23]. It is known that the cardiac type $3 \mathrm{Na}^{+} / 1 \mathrm{Ca}^{2+}$ exchanger is dominant in brain [23]. Thus, we have used the same exchange for our model. We know that the amount of energy required to extrude an ion against its concentration gradient is given by [21, 20,9],

$$
\Delta_{S}=z_{S} F V_{m}+R T \log \left(\frac{S_{i}}{S_{o}}\right)
$$

where, $S$ is the extruded ion. Introducing energy barrier, $\eta$, and using the fact that

$$
\Delta_{C a}=3 \Delta_{N a}
$$


we can write NCX current equation with an allosteric dependence over $\left[\mathrm{Ca}^{2+}\right]$ as [13],

$$
\begin{gathered}
I_{N C X}=\frac{\left[C a^{2+}\right]^{H, N C X}}{\left[C a^{2+}\right]^{H, N C X}+K_{m}^{H, N C X}} g_{N C X} \\
\times \frac{\left[N a^{+}\right]^{3}\left[C a^{2+}\right]_{o} \exp \left(\eta \frac{F V_{m}}{R T}\right)-\left[N a^{+}\right]_{o}^{3}\left[C a^{2+}\right] \exp \left((\eta-1) \frac{F V_{m}}{R T}\right)}{1+d_{N C X}\left(\left[N a^{+}\right]_{o}^{3}\left[C a^{2+}\right]+\left[N a^{+}\right]^{3}\left[C a^{2+}\right]_{o}\right)}
\end{gathered}
$$

where, $\left[\mathrm{Ca}^{2+}\right]_{o}$ is the extracellular $\mathrm{Ca}^{2+}$ concentration (in $\mathrm{mM}$ ), $\left[\mathrm{Na}^{+}\right]$is the intracellular $\mathrm{Na}^{+}$concentration (in $\mathrm{mM}$ ), $\left[\mathrm{Na}^{+}\right]_{o}$ is the extracellular $\mathrm{Na}^{+}$concentration (in mM), $K_{m}^{H, N C X}$ is the $\mathrm{Ca}^{2+}$ concentration at which $I_{N C X}$ is halved, $H, N C X$ is the Hill's coefficient of NCX, $d_{N C X}$ is constant for saturability of $I_{N C X}, g_{N C X}$ is the conductance of $N C X$ (in $\left.\mathrm{nS}\right)$.

\section{$2.4 \mathrm{Na}^{+} / \mathrm{K}^{+}$ATPase}

$\mathrm{Na}^{+} / \mathrm{K}^{+}$ATPase $(\mathrm{NaK})$ is also a P-type ATPase which is also known as the sodium pump and is a $147 \mathrm{kDa}$ membrane protein [24]. It is known for the extrusion of $\mathrm{Na}^{+}$ions at an expense of some ATP and inflow of $\mathrm{K}^{+}$ions. Its formulation is based on the steps given by Holmgren et al. [14], where he used high speed voltage jumps to determine three distinct steps of $\mathrm{Na}^{+}$ions deocclusion from the pump. The current through the sodium pump has the following form,

$$
\hat{I}_{N a K}=\frac{I_{N a K}}{\tau_{N a K}}\left(k_{f}+\frac{k_{b}}{1+\left(\frac{K_{0.5}(0) \exp \left(\lambda \frac{F V_{m}}{R T}\right)}{\left[N a^{+}\right]_{o}}\right)^{H, N a K}}\right)
$$

here, $I_{\mathrm{NaK}}$ is the scaling factor of $\mathrm{NaK}$ current (in $\mu \mathrm{A} / \mathrm{cm}^{2}$ ), $k_{f}$ (in $\mathrm{ms}$ ) is the forward (deocclusion) rate constant, $k_{b}$ (in ms) is the backward (occlusion) rate constant, $K_{0.5}(0)$ is half activating $\left[\mathrm{Na}^{+}\right]_{o}$ concentration at $0 \mathrm{mV}$, $H, N a K$ is the Hill's coefficient for half activating NaK current, $\lambda$ is the fraction of electrical field dropped along the access channel and $\tau_{N a K}$ (in $\mathrm{ms}$ ) is some constant. 


\subsection{Cytosolic $\mathrm{Ca}^{2+}$ buffers}

It is assumed that a single buffer specie is present inside the cytosol and follows the following bi-molecular reaction

$$
\left[C a^{2+}\right]+[B] \underset{k^{-}}{\stackrel{k^{+}}{\rightleftharpoons}}[C a B]
$$

and which can be formulated in terms of the following differential equations,

$$
\begin{gathered}
\frac{d\left[\mathrm{Ca}^{2+}\right]}{d t}=-k^{+}\left[\mathrm{Ca}^{2+}\right][B]+k^{-}[\mathrm{CaB}] \\
\frac{d[B]}{d t}=-k^{+}\left[C a^{2+}\right][B]+k^{-}[\mathrm{CaB}] \\
\frac{d[C a B]}{d t}=k^{+}\left[C a^{2+}\right][B]-k^{-}[\mathrm{CaB}]
\end{gathered}
$$

If we also assume that there are no sources and no sinks present for buffer. Then letting $B_{T}$ represent the total buffer concentration, the above equation can be written in the reduced form as,

$$
\begin{gathered}
\frac{d\left[C a^{2+}\right]}{d t}=-k^{+}\left[C a^{2+}\right]\left[B_{T}-[C a B]\right]+k^{-}[C a B] \\
\frac{d[C a B]}{d t}=k^{+}\left[C a^{2+}\right]\left[B_{T}-C a B\right]-k^{-}[C a B]
\end{gathered}
$$

where, $k^{+}$is the buffer association rate, $k^{-}$is the buffer dissociation rate, $[\mathrm{CaB}]$ represents bound buffer concentration.

\section{$2.6 \mathrm{Na}^{+}$and $\mathrm{K}^{+}$channels}

To generate action potentials $\mathrm{Na}^{+}$current and $\mathrm{K}^{+}$channels are taken as modeled by Hodgkin and Huxley [15]. The transmembrane current due to $\mathrm{Na}^{+}$and $\mathrm{K}^{+}$ channels has been modeled using the linear current-voltage relationship derived with the help of Ohm's Law,

$$
I_{S}=g_{S}\left(V_{m}-V_{S}\right)
$$

where, $S$ is either $\mathrm{Na}^{+}$or $\mathrm{K}^{+}$ion, $g_{S}$ is conductance of the given ion, $V_{S}$ is the reversal potential of the given ion determined by Nernst Equilibrium Potential 
equation (or simply Nernst equation),

$$
V_{S}=1000 \frac{R T}{z_{S} F} \log \left(\frac{S_{o}}{S_{i}}\right)
$$

where, 1000 is used to convert volts into milli-volts. All other symbols have their usual meanings. Here, and in all other instances, individual ionic reversal potential has been determined using Nernst equation at each integration step during runtime.

\section{7 $\mathrm{Ca}^{2+}$ activated small and intermediate $\mathrm{K}^{+}$channel}

The current through $\mathrm{SK}_{C a}$ is modeled using a linear current voltage relation as follows,

$$
\begin{gathered}
I_{S K_{C a}}=g_{S K_{C a}} P_{o, S K_{C a}}\left(V_{m}-V_{K}\right) \\
P_{o, S K_{C a}}=\frac{\left[C a^{2+}\right]_{i}^{n_{S K_{C a}}}}{\left[C a^{2+}\right]_{i}^{n_{S K_{C a}}}+K_{S K_{C a}}^{n_{S K_{C a}}}}
\end{gathered}
$$

Here, $g_{S K_{C a}}$ is $\mathrm{SK}_{C a}$ channel conductance per unit area (in $\mathrm{mS} / \mathrm{cm}^{2}$ ), $P_{o, S K_{C a}}$ is its $\mathrm{Ca}^{2+}$ dependent open probability, $V_{K}$ is the reversal potential of $K^{+}$ions. Similarly, $\mathrm{Ca}^{2+}$ activated intermediate $\mathrm{K}^{+}$current is modeled using a linear current voltage relation as follows,

$$
\begin{gathered}
I_{I K_{C a}}=g_{I K_{C a}} P_{o, I K_{C a}}\left(V_{m}-V_{K}\right) \\
P_{o, I K_{C a}}=\frac{\left[C a^{2+}\right]_{i}^{n_{I K_{C a}}}}{\left[C a^{2+}\right]_{i}^{n_{I K_{C a}}}+K_{I K_{C a}}^{n_{I K_{C a}}}}
\end{gathered}
$$

Here, $g_{I K_{C a}}$ is $I K_{C a}$ channel conductance per unit area (in $\left.\mathrm{mS} / \mathrm{cm}^{2}\right), P_{o, I K_{C a}}$ is its $\mathrm{Ca}^{2+}$ dependent open probability, $V_{K}$ is the reversal potential of $\mathrm{K}^{+}$ions.

\subsection{Inward rectifier $\mathrm{K}^{+}$channel}

Inward rectifier $\mathrm{K}^{+}$current is known to contribute to resting membrane potential. It is also modeled using the linear current voltage relationship,

$$
I_{K_{i r}}=g_{K_{i r}} \sqrt{\frac{\left[K^{+}\right]_{o}}{K_{o s t}}} \frac{\alpha}{\alpha+\beta}\left(V_{m}-V_{K}\right)
$$


where,

$$
\begin{gathered}
\alpha=\frac{0.1}{1+\exp \left(0.06\left(V_{m}-V_{K}-50\right)\right)} \\
\beta=\frac{3 \exp \left(0.0002\left(V_{m}-V_{K}+100\right)\right)+\exp \left(0.0002\left(V_{m}-V_{K}-10\right)\right)}{1+\exp \left(-0.06\left(V_{m}-V_{K}-50\right)\right)}
\end{gathered}
$$

and $g_{K_{i r}}$ is the $\mathrm{K}_{i r}$ conductance (in $\mathrm{nS}$ ), $V_{K}$ is the reversal potential for $\mathrm{K}^{+}$ given by Nernst equation, $\left[\mathrm{K}^{+}\right]_{o}$ is the extracellular $\mathrm{K}^{+}$ion concentration. Here, $g_{K_{i r}}$ is converted into $\mathrm{mS} / \mathrm{cm}^{2}$ using $\mathrm{A}_{c a p}$ before being used in the equation governing membrane potential.

\section{$2.9 \mathrm{Ca}^{2+}$ and $\mathrm{Na}^{+}$leak currents}

To balance the net effect of $I_{N C X}$ and $I_{\text {pump }}$ there is supposed to be a $\mathrm{Ca}^{2+}$ leak current given by,

$$
I_{C a, b}=g_{C a, b}\left(V_{m}-V_{C a}\right)
$$

where, $g_{C a, b}$ is the $\mathrm{Ca}^{2+}$ leak conductance per unit area (in $\mathrm{mS} / \mathrm{cm}^{2}$ ), $V_{C a}$ is the reversal potential (in $\mathrm{mV}$ ) for $\mathrm{Ca}^{2+}$ given by Nernst equation. Similarly, we can formulate $\mathrm{Na}^{+}$leak current to balance the net effect of $I_{N C X}$ and $\hat{I}_{N a K}$,

$$
I_{N a, b}=g_{N a, b}\left(V_{m}-V_{N a}\right)
$$

where, $g_{N a, b}$ is the $\mathrm{Na}^{+}$leak conductance per unit area (in $\mathrm{mS} / \mathrm{cm}^{2}$ ), $V_{N a}$ is the reversal potential (in $\mathrm{mV}$ ) for $\mathrm{Na}^{+}$given by Nernst equation. The current due to all other ions is considered as leak and is incorporated as,

$$
I_{L}=g_{L}\left(V_{m}-V_{L}\right)
$$

where, $g_{L}$ is leak conductance (in $\mathrm{mS} / \mathrm{cm}^{2}$ ) and $V_{L}$ is leak reversal potential assumed to be constant.

\subsection{Membrane potential}

Like the formulation of Hodgkin and Huxley [15] we have divided the total membrane current into capacitive current and ionic currents. Thus, for capacitive current we have,

$$
C_{m} \frac{d V_{m}}{d t}=I_{a p p}-I_{i}
$$


where, $I_{a p p}$ is the applied membrane current density (in $\mu \mathrm{A} / \mathrm{cm}^{2}$ ), $V_{m}$ is the membrane potential (in $\mathrm{mV}), C_{m}$ is the specific membrane capacitance $\left(\mu \mathrm{F} / \mathrm{cm}^{2}\right)$, $I_{i}$ accounts for all the transmembrane currents discussed earlier and $t$ is time (in $\mathrm{ms}$ ). The gating mechanism of the transmembrane currents follows Hodgkin and Huxley [15]. Combining equation (1)-(13) we can write the mathematical model governing $\mathrm{CaOs}$ with relevance to $\mathrm{Na}^{+}$and $\mathrm{K}^{+}$ions, as in the case of an action potential as,

$$
\begin{gathered}
\frac{d\left[\mathrm{Ca}^{2+}\right]}{d t}=-\sigma_{C a}+2 \sigma_{N C X}-\sigma_{\text {pump }}-\sigma_{C a, b} \\
-k^{+}\left[\mathrm{Ca}^{2+}\right]\left(B_{T}-[C a B]\right)+k^{-}[C a B] \\
\frac{d[C a B]}{d t}=k^{+}\left[C a^{2+}\right]\left(B_{T}-[C a B]\right)-k^{-}[C a B] \\
\frac{d\left[N a^{+}\right]}{d t}=-\sigma_{N a}-3 \sigma_{N C X}-3 \sigma_{N a K}-\sigma_{N a, b}-\sigma_{N a, L} \\
\frac{d\left[K^{+}\right]}{d t}=-\sigma_{K}-\sigma_{S K_{C a}}-\sigma_{I K_{C a}}-\sigma_{K_{i r}}-\sigma_{K, L}+2 \sigma_{N a K} \\
C_{m} \frac{d V_{m}}{d t}=I_{a p p}-m_{c} h_{c} v_{C a} I_{C a, t}-m^{3} h I_{N a}-n^{4} I_{K} \\
-I_{N C X}-\hat{I}_{N a K}-I_{N a, b}-I_{C a, b} \\
-I_{K_{i r}}-I_{S K_{C a}}-I_{I K_{C a}}-\hat{I}_{p u m p}-I_{L}
\end{gathered}
$$

In equation (14),

$$
\alpha_{i}, \beta_{i}\left(i=m, n, h, m_{c}, h_{c}\right)
$$

are rate constants which vary with membrane potential but not with time $\left(m s^{-1}\right)$ and $m, n, h, m_{c}, h_{c}$ are dimensionless gating variables with values lying between 0 and 1 . In this model we assume that fluxes from $\mathrm{IP}_{3} \mathrm{Rs}$ are absent. This can be achieved by blocking $\mathrm{IP}_{3} \mathrm{R}$ channel by using an $\mathrm{IP}_{3} \mathrm{R}$ antagonist like heparin [25]. This assumption has been taken to exclude the effect of intracellular stores over CaOs. The initial condition of the system is,

$$
\left[\mathrm{Ca}^{2+}\right]=0.0001,\left[\mathrm{Na}^{+}\right]=12,\left[\mathrm{~K}^{+}\right]=135,[\mathrm{CaB}]=0.0023
$$


All ionic concentrations are in the units of $\mathrm{mM}$. The ordinary differential equations governing the gating variables $\left(m, n, h, m_{c}, h_{c}\right)$ are

$$
\begin{gathered}
\frac{d m}{d t}=\alpha_{m}(1-m)-\beta_{m} m \\
\frac{d n}{d t}=\alpha_{n}(1-n)-\beta_{n} n \\
\frac{d h}{d t}=\alpha_{h}(1-h)-\beta_{h} h \\
\frac{d m_{c}}{d t}=\alpha_{m_{c}}\left(1-m_{c}\right)-\beta_{m_{c}} m_{c} \\
\frac{d h_{c}}{d t}=\alpha_{h_{c}}\left(1-h_{c}\right)-\beta_{h_{c}} h_{c}
\end{gathered}
$$

Here, $m$ and $(1-m)$ are representing on and off state of the variable $m$, respectively. Variables $n, h, m_{c}$ and $h_{c}$ also follow likewise. The mathematical expressions of the voltage-dependent rate constants in equation (14) are as follows,

$$
\begin{gathered}
\alpha_{n}=\frac{0.01\left(-V_{m}-60\right)}{\exp \left(\frac{-V_{m}-60}{10}\right)-1} ; \beta_{n}=0.125 \exp \left(\frac{-V_{m}-70}{80}\right) \\
\alpha_{m}=\frac{0.1\left(-V_{m}-45\right)}{\exp \left(\frac{-V_{m}-45}{10}\right)-1} ; \beta_{m}=4 \exp \left(\frac{-V_{m}-70}{18}\right) \\
\alpha_{h}=0.07 \exp \left(\frac{-V_{m}-70}{20}\right) ; \beta_{n}=\frac{1}{\exp \left(\frac{-V_{m}-40}{10}\right)+1} \\
\alpha_{m_{c}}=\frac{0.1\left(-V_{m}-\tilde{V}-45\right)}{\exp \left(\frac{-V_{m}-\tilde{V}-45}{10}\right)-1} ; \beta_{m_{c}}=4 \exp \left(\frac{-V_{m}-\tilde{V}-70}{18}\right) \\
\alpha_{h_{c}}=0.07 \exp \left(\frac{-V_{m}-\tilde{V}-70}{20}\right) ; \beta_{n_{c}}=\frac{\exp \left(\frac{-V_{m}-\tilde{V}-40}{10}\right)+1}{v_{C a}=\frac{K_{v_{C a}}}{\left[C a^{2+}\right]+K_{v_{C a}}}}
\end{gathered}
$$


For the solution of equations (14)-(16), we have used Euler's method and written a script in MATLAB that has been simulated on an AMD Turion $64 \times 2$ machine with $1.6 \mathrm{GHz}$ processing speed and $2.5 \mathrm{~GB}$ memory. The time taken per simulation is $\sim 9 \mathrm{sec}$ when simulating for $30 \mathrm{~ms}$ using 4000 time steps i.e. $\Delta t=0.0075 \mathrm{~ms}$. The numerical results obtained are used to study the effect of varying transmembrane currents over $\mathrm{CaO}$ s which are discussed in the following section.

\section{Results and discussion}

In all the figures, it is assumed that cytosolic $\mathrm{Ca}^{2+}$ is buffered with $50 \mu \mathrm{M}$ Ethylene Glycol Tetraacetic Acid (EGTA). The standard biophysical parameters used for simulation of the model are listed in Table 1-4 unless stated along with the figures. Since our main objective is to study $\mathrm{CaOs}$, we have shown results that are pertinent to $\mathrm{CaOs}$ only.

\begin{tabular}{c|c|c|c}
\hline Symbol & Parameter & Value & Reference \\
\hline$g_{N a}$ & $\mathrm{Na}^{+}$conductance & $120 \mathrm{mS} / \mathrm{cm}^{2}$ & {$[15]$} \\
$g_{K}$ & $\mathrm{~K}^{+}$conductance & $36 \mathrm{mS} / \mathrm{cm}^{2}$ & {$[15]$} \\
$g_{L}$ & Leak conductance & $0.3 \mathrm{mS} / \mathrm{cm}^{2}$ & {$[15]$} \\
$g_{C a, b}$ & $\mathrm{Ca}^{2+}$ leak conductance & $0.001 \mathrm{mS} / \mathrm{cm}^{2}$ & - \\
$g_{N a, b}$ & $\mathrm{Na}^{+}$leak conductance & $0.0014 \mathrm{mS} / \mathrm{cm}^{2}$ & {$[17,18]$} \\
$g_{K i r}$ & $K_{i r}$ conductance & $0.95 \mathrm{mS} / \mathrm{cm}^{2}$ & - \\
$g_{N C X}$ & $\mathrm{NCX}$ conductance & $1.99 \mathrm{nS}$ & {$[13]$} \\
$g_{S K_{C a}}$ & $\mathrm{SK}_{C a}$ conductance & $0.62 \mathrm{nS}$ & {$[13]$} \\
$g_{I K_{C a}}$ & $\mathrm{IK}_{C a}$ conductance & $1.72 \mathrm{nS}$ & {$[13]$} \\
\hline
\end{tabular}

Table 1 - Maximal conductance of channels \& leaks.

In Figure 2 we observe the effect of an impulse of $10 \mu \mathrm{A} / \mathrm{cm}^{2}$ over membrane potential. Such an effect has been studied in great detail by Hodgkin and Huxley [15], Luo and Rudy $[16,17,18]$ thus, we need not give much emphasis over it here. In Figure 3, we have shown different current densities. All these current densities result in the shown action potential. The rest of the results shown are relevant to $\mathrm{CaOs}$ and has been studied in detail in the following figures. 


\begin{tabular}{c|c|c}
\hline Symbol & Parameter & Value \\
\hline $\mathrm{F}$ & Faraday's Constant & 96487 Coulombs $/$ mole \\
$\mathrm{R}$ & Real gas constant & $8.314 \mathrm{~J} / \mathrm{K}$ mole \\
$\mathrm{T}$ & Absolute temperature & $293.15 \mathrm{~K}$ \\
$z_{C a}$ & $\mathrm{Ca}^{2+}$ valence & 2 \\
$z_{N a}$ & $\mathrm{Na}^{+}$valence & 1 \\
$z_{K}$ & $\mathrm{~K}^{+}$valence & 1 \\
$C_{m}$ & Cell capacitance & $1 \mu \mathrm{F} / \mathrm{cm}^{2}$ \\
$I_{a p p}$ & Applied current density & $10 \mu \mathrm{A} / \mathrm{cm}^{2}$ \\
$V_{c y t}$ & Cell Volume & $4.2 \times 10^{-6} \mu \mathrm{L}$ \\
$A_{c a p}$ & Cell Surface area & $1.26 \times 10^{-5} \mathrm{~cm}^{2}$ \\
\hline
\end{tabular}

Table 2 - Some electrophysiological constants.

\begin{tabular}{c|l|c|c}
\hline Symbol & Parameter & Value & Reference \\
\hline$P_{C a}$ & $\mathrm{Ca}^{2+}$ Permeability & $5.4 \times 10^{-4} \mathrm{~cm} / \mathrm{sec}$ & {$[19]$} \\
$P_{N a}$ & $\mathrm{Na}^{+}$Permeability & $1.5 \times 10^{-8} \mathrm{~cm} / \mathrm{sec}$ & {$[19]$} \\
$P_{K}$ & $\mathrm{~K}^{+}$Permeability & $2.7 \times 10^{-7} \mathrm{~cm} / \mathrm{sec}$ & {$[19]$} \\
{$\left[\mathrm{Ca}^{2+}\right]_{o}$} & Extracellular $\left[\mathrm{Ca}^{2+}\right]$ & $1.8 \mathrm{mM}$ & {$[19]$} \\
{$\left[\mathrm{Na}^{+}\right]_{o}$} & Extracellular $\left[\mathrm{Na}^{+}\right]$ & $145 \mathrm{mM}$ & {$[19]$} \\
{$\left[K^{+}\right]_{o}$} & Extracellular $\left[\mathrm{K}^{+}\right]$ & $5.4 \mathrm{mM}$ & {$[19]$} \\
$\gamma_{i, C a}$ & a.c. of $\left[\mathrm{Ca}^{2+}\right]$ & 0.341 & {$[16,17,19]$} \\
$\gamma_{o}, \mathrm{Ca}$ & a.c. of $\left[\mathrm{Ca}^{2+}\right]_{o}$ & 1 & {$[16,17,19]$} \\
$\gamma_{i, N a}$ & a.c. of $\left[\mathrm{Na}^{+}\right]$ & 0.75 & {$[16,17,19]$} \\
$\gamma_{o}, \mathrm{Na}$ & a.c. of $\left[\mathrm{Na}^{+}\right]_{o}$ & 0.75 & {$[16,17,19]$} \\
$\gamma_{i, K}$ & a.c. of $\left[\mathrm{K}^{+}\right]$ & 0.75 & {$[16,17,19]$} \\
$\gamma_{o}, K$ & a.c. of $\left[\mathrm{K}^{+}\right]_{o}$ & 0.75 & {$[16,17,19]$} \\
$k^{+}$ & EGTA association rate & $1.5 \mu M^{-1} s^{-1}$ & {$[11]$} \\
$k^{-}$ & EGTA dissociation rate & $0.3 s^{-1}$ & {$[11]$} \\
$B_{T}$ & Total intracellular buffer & $50 \mu \mathrm{M}$ & - \\
\hline
\end{tabular}

Table 3 - Some biochemical constants. 


\begin{tabular}{|c|c|c|c|}
\hline Symbol & Parameter & Value & Reference \\
\hline$V_{L}$ & Leak reversal potential & $10.6 \mathrm{mV}$ & {$[15]$} \\
\hline$K_{\text {ost }}$ & Regulatory parameter for $\mathrm{K}_{i r}$ & $5.4 \mu \mathrm{M}$ & {$[12]$} \\
\hline$K_{v_{C a}}$ & $\mathrm{Ca}^{2+}$ affinity of $\mathrm{Ca}^{2+}$ channel & $10 \mu \mathrm{M}$ & {$[12]$} \\
\hline$\tilde{V}$ & $\mathrm{Ca}^{2+}$ channel voltage shift & $15 \mathrm{mV}$ & - \\
\hline$\eta$ & NCX energy barrier & 0.483 & {$[13]$} \\
\hline$d_{N C X}$ & NCX constant & $3.04 \times 10^{-4}$ & {$[13]$} \\
\hline$K_{m}^{H, N C X}$ & $\mathrm{Ca}^{2+}$ affinity of $\mathrm{NCX}$ & $0.256 \times 10^{-3}$ & {$[13]$} \\
\hline $\mathrm{H}, \mathrm{NCX}$ & Hill-coefficient of NCX & 1.5 & {$[13]$} \\
\hline$I_{N a K}$ & Scaling factor of sodium pump & $1.5 \mu \mathrm{A} / \mathrm{cm}^{2}$ & - \\
\hline$k_{f}$ & $\mathrm{NaK}$ de-occlusion rate & $0.097 \mathrm{~ms}$ & {$[14]$} \\
\hline$k_{b}$ & NaK occlusion rate & $1.444 \mathrm{~ms}$ & {$[14]$} \\
\hline$K_{0.5}(0)$ & {$\left[\mathrm{Na}^{+}\right]_{o}$ when $I_{\mathrm{NaK}}$ is halved } & $6.95 \times 10^{-3} \mathrm{mM}$ & {$[14]$} \\
\hline$\lambda$ & $\begin{array}{l}\text { Electric field dropped } \\
\text { along } \mathrm{NaK}\end{array}$ & 0.71 & {$[14]$} \\
\hline $\mathrm{H}, \mathrm{NaK}$ & Hill-coeffcient of $\mathrm{NaK}$ & 1.17 & {$[14]$} \\
\hline$\tau_{N a K}$ & Constant for $I_{N a K}$ & $0.2834 \mathrm{~ms}$ & - \\
\hline$I_{\text {pump }}$ & Maximal PMCA current & $2.67 \mathrm{pA}$ & {$[13]$} \\
\hline$K_{m}^{H, p u m p}$ & $\mathrm{Ca}^{2+}$ affinity of PMCA & $0.26 \times 10^{-3} \mathrm{mM}$ & {$[13]$} \\
\hline H,pump & Hill-coeffcient of PMCA & 1.4 & {$[13]$} \\
\hline$n_{S K_{C a}}$ & Hill-coeffcient of $\mathrm{SK}_{C a}$ & 1.6 & {$[13]$} \\
\hline$K_{S K_{C a}}$ & $\mathrm{Ca}^{2+}$ affinity of $\mathrm{SK}_{C a}$ & $237 \times 10^{-6} \mathrm{mM}$ & {$[13]$} \\
\hline$n_{I K_{C a}}$ & Hill-coeffcient of $\mathrm{IK}_{C a}$ & 1.4 & {$[13]$} \\
\hline$K_{I K_{C a}}$ & $\mathrm{Ca}^{2+}$ affinity of $\mathrm{IK}_{C a}$ & $740 \times 10^{-6} \mathrm{mM}$ & {$[13]$} \\
\hline
\end{tabular}

Table 4 - All other biophysical constants.

In Figure 4 we have shown $\mathrm{Ca}^{2+}$ oscillation and buffered $\mathrm{Ca}^{2+}$ curves with respect to standard parameters listed in Table 1. Initially it was assumed that $2.3 \mu{\mathrm{M} \mathrm{of} \mathrm{Ca}^{2+}}^{2}$ is buffered. Further it is apparent from Figure 4 that the amplitude of first $\mathrm{Ca}^{2+}$ spike is more than the second spike. It is because of the slow dissociation constant of EGTA which results in higher buffered $\mathrm{Ca}^{2+}$ and lower cytosolic $\mathrm{Ca}^{2+}$ concentration. Comparing Figure 4 with Figure 2, it is clear that both of them are positively correlated. As membrane potential rises the $\mathrm{Ca}^{2+}$ concentration rises and when membrane potential drops $\mathrm{Ca}^{2+}$ concentration drops. 


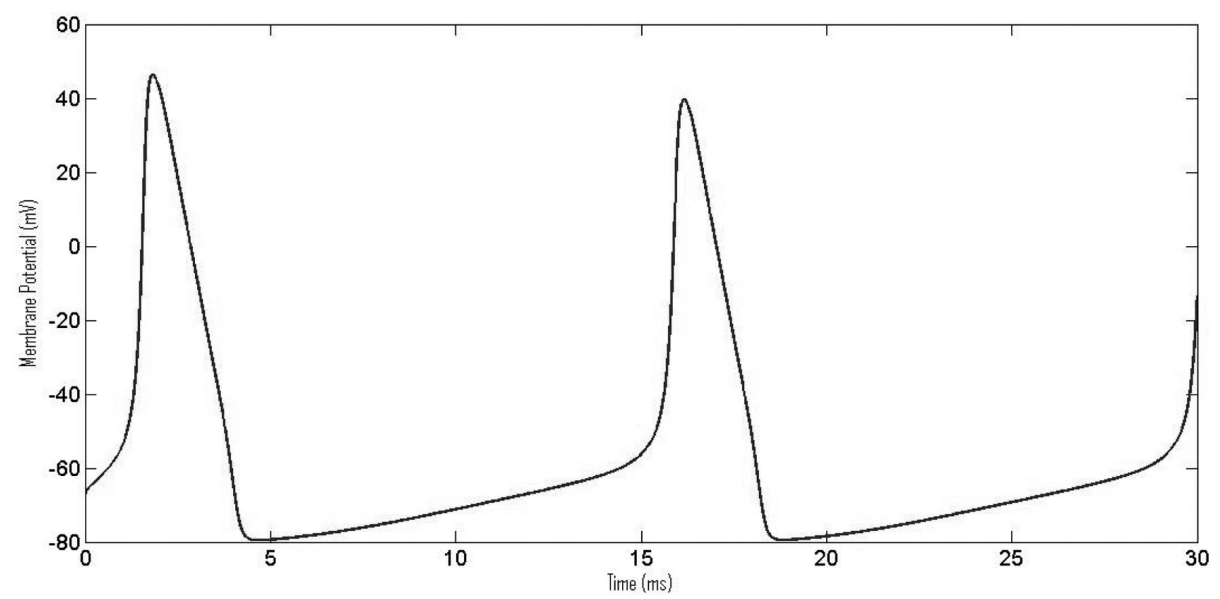

Figure 2 - Changing membrane potential during an action potential in response to an applied current of $10 \mu \mathrm{Acm}^{-2}$.
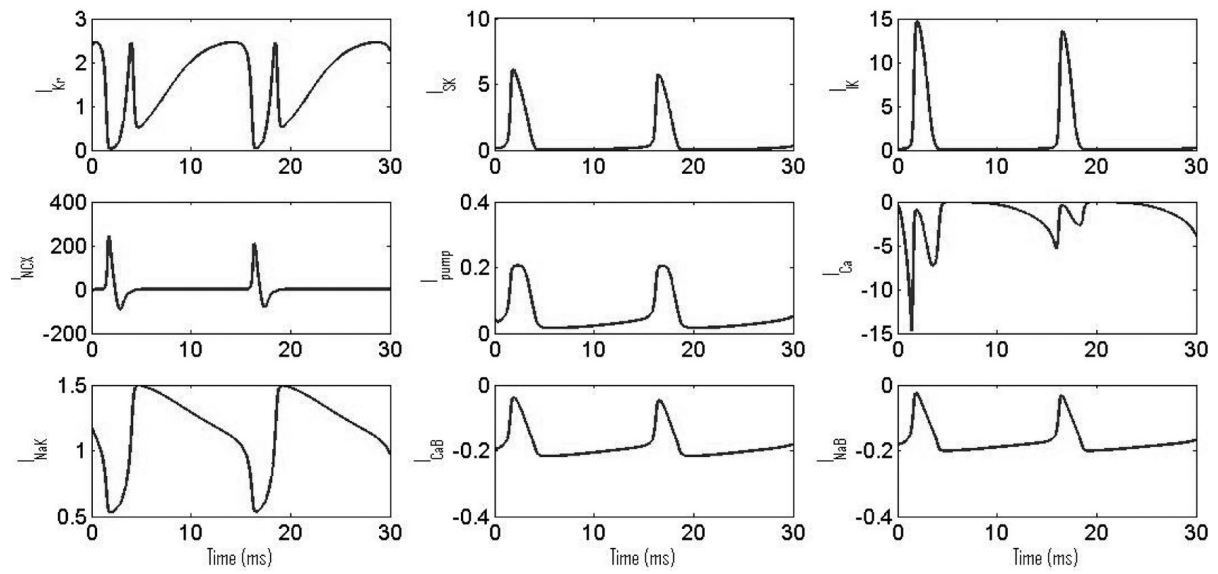

Figure 3 - Behavior of various current densities during action potential (A) Inward rectifier potassium current, $I_{K_{i r}}(\mathrm{~B}) \mathrm{Ca}^{2+}$ induced small potassium current, $I_{S K_{C a}}(\mathrm{C})$ $\mathrm{Ca}^{2+}$ induced intermediate potassium current, $I_{I K_{C a}}$ (D) $\mathrm{Na}^{+} / \mathrm{Ca}^{2+}$ exchanger current, $I_{N C X}(\mathrm{E}) \mathrm{PM} \mathrm{Ca}^{2+}$ ATPase current, $I_{\text {pump }}(\mathrm{F}) \mathrm{L}$-type $\mathrm{Ca}^{2+}$ current, $I_{C a}(\mathrm{G}) \mathrm{Na}^{+} / \mathrm{K}^{+}$ ATPase current, $I_{N a K}(\mathrm{H}) \mathrm{Ca}^{2+}$ leak current, $I_{C a, B}(\mathrm{I}) \mathrm{Na}^{+}$leak current, $I_{N a, B}$. 

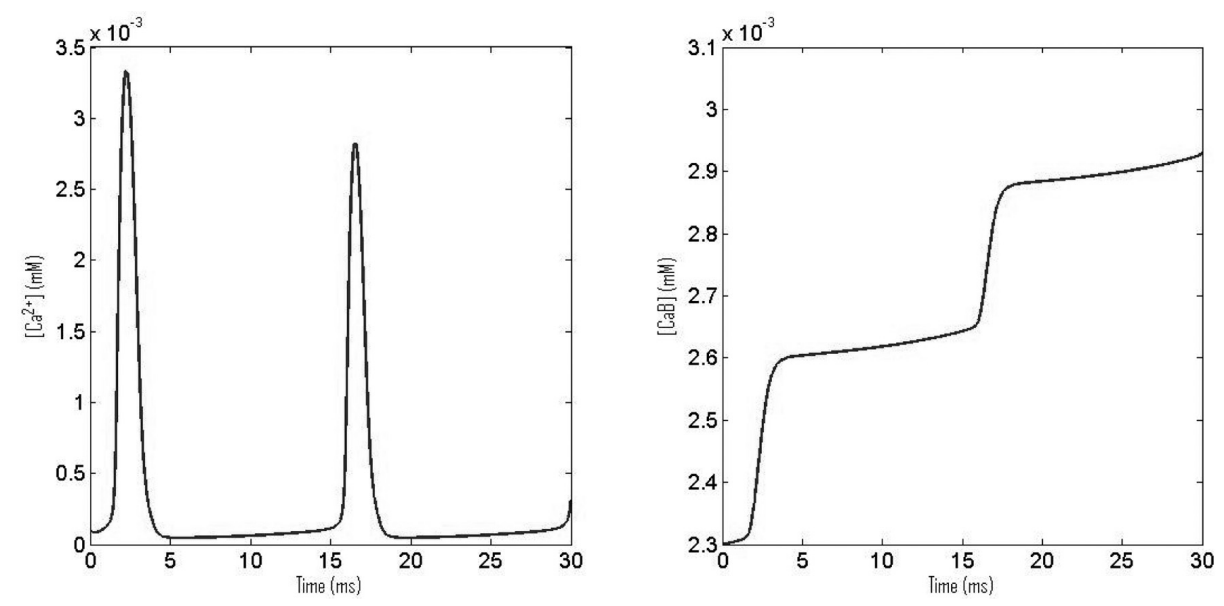

Figure 4 - (A) $\mathrm{CaOs}$ in response of an applied current of $10 \mu \mathrm{Acm}^{-2}$ and (B) corresponding bound $\mathrm{Ca}^{2+}$ concentration.

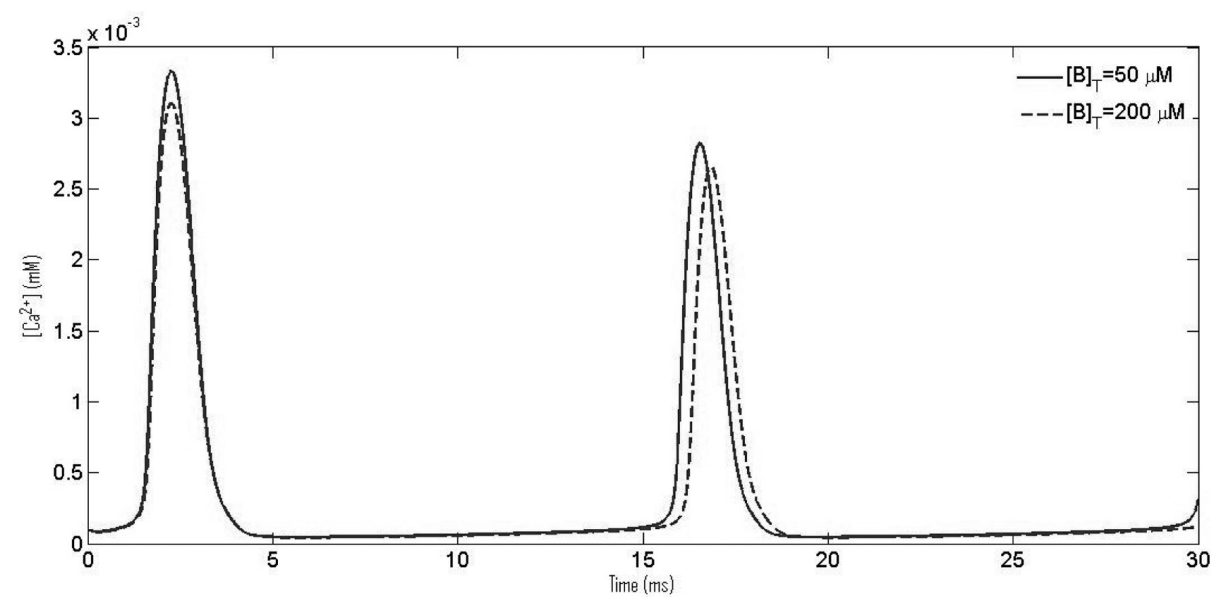

Figure $5-\mathrm{CaOs}$ with increasing total buffer concentration $B_{T}$.

In Figure 5 the effect of increasing total buffer concentration of EGTA is shown. The results are shown for $B_{T}=50 \mu \mathrm{M}$ (dark line) and $B_{T}=200 \mu \mathrm{M}$ (broken line). As expected increasing buffer concentration results in lower amplitude of $\mathrm{Ca}^{2+}$ oscillation, which is also evident from Figure 5.

In Figure 6 we observe the effect of increasing NCX conductance. Our simulation is in support of the biological fact that at negative potentials NCX works in reverse direction i.e. outflow of $\mathrm{Ca}^{2+}$ ions and inflow of $3 \mathrm{Na}^{+}$ions. As increas- 


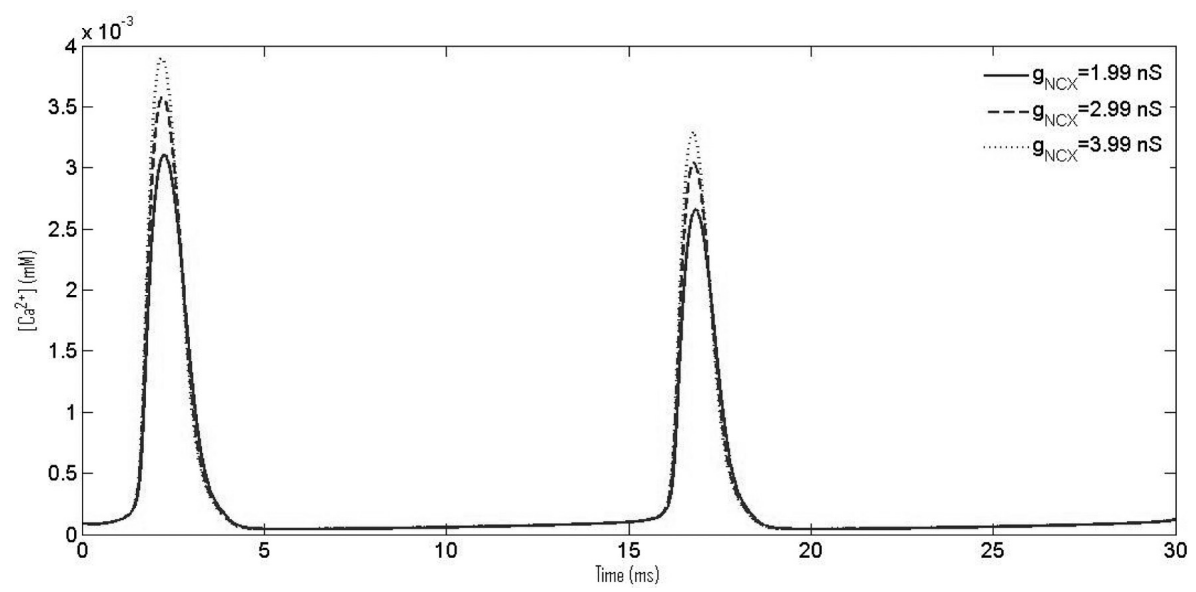

Figure $6-\mathrm{CaOs}$ with increasing NCX conductance, $g_{N C X}$.

ing NCX conductance results in higher amplitude of $\mathrm{Ca}^{2+}$ oscillation while there is no change resting $\mathrm{Ca}^{2+}$ concentration at more positive membrane potentials as we have used a leak to neutralize the effect of NCX and pump currents.

In Figure 7 we observe the results for which the mathematical model was proposed. It is widely believed that cells encode information in the frequency of $\mathrm{Ca}^{2+}$ oscillations rather than its amplitude. There are a number of authors who have shown different roles of this ubiquitous sodium pump [26,27]. Matchkov et al. [27] also experimentally demonstrated that sodium pump plays a significant role in regulating $\mathrm{CaOs}$ via regulation of cytosolic $\mathrm{Na}^{+}$ions. Similar philosophy is suggested by our present simulations. We increased pumping rate, $I_{\mathrm{NaK}}=$ $1.5 \mu \mathrm{A} / \mathrm{cm}^{2}$ (dark line), $3 \mu \mathrm{A} / \mathrm{cm}^{2}$ (broken line), $4.5 \mu \mathrm{A} / \mathrm{cm}^{2}$ (dotted line), of sodium pump and observed changes in CaOs. It is seen that an increase in $I_{\mathrm{NaK}}$ results in an increase in the period of $\mathrm{Ca}^{2+}$ oscillations. The changes were quite apparent and are reflected from Figure 7.

In Figures 8-10, the effect of different extracellular concentrations of $\mathrm{Ca}^{2+}, \mathrm{K}^{+}$ and $\mathrm{Na}^{+}$are shown over CaOs. The findings of Figure 8 are quite obvious but should be mentioned to show accordance with the biological facts. The curves are shown for $\left[\mathrm{Ca}^{2+}\right]_{o}=1.8 \mathrm{mM}$ (dark line) and $\left[\mathrm{Ca}^{2+}\right]_{o}=1 \mathrm{mM}$ (broken line). It is apparent from Figure 8 that lowering $\left[\mathrm{Ca}^{2+}\right]_{o}$ results in lower amplitude of $\mathrm{Ca}^{2+}$ oscillation which is because of a corresponding decrease in $\mathrm{Ca}^{2+}$ gradient.

In Figure 9, the findings are worth mentioning as an increase in $\left[\mathrm{K}^{+}\right]_{o}$ con- 


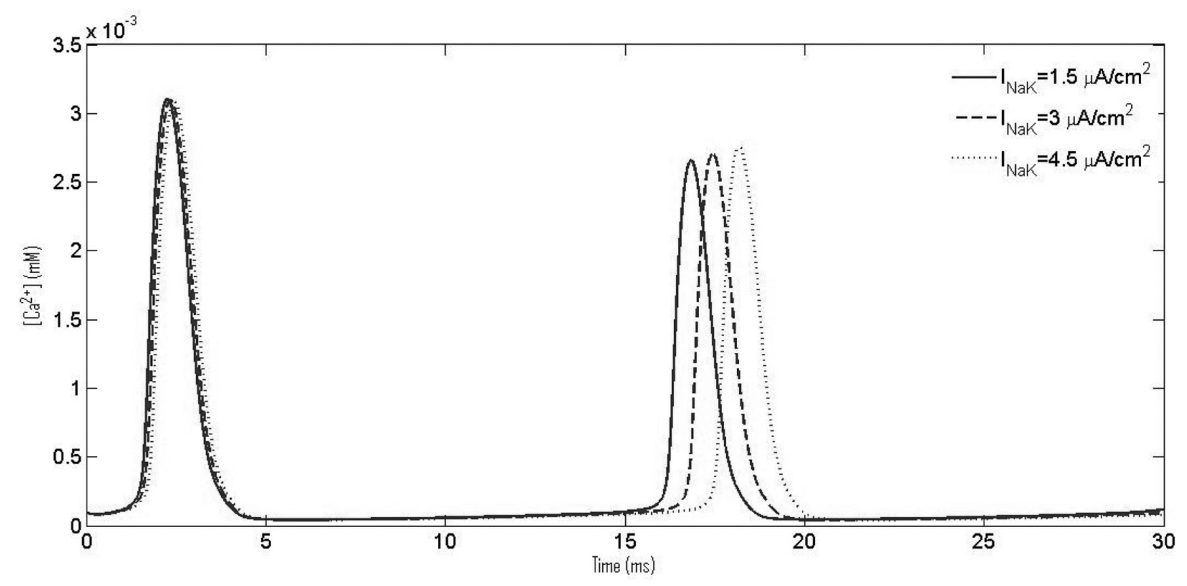

Figure $7-\mathrm{CaOs}$ with increasing $\mathrm{NaK}$ current, $I_{\mathrm{NaK}}$.

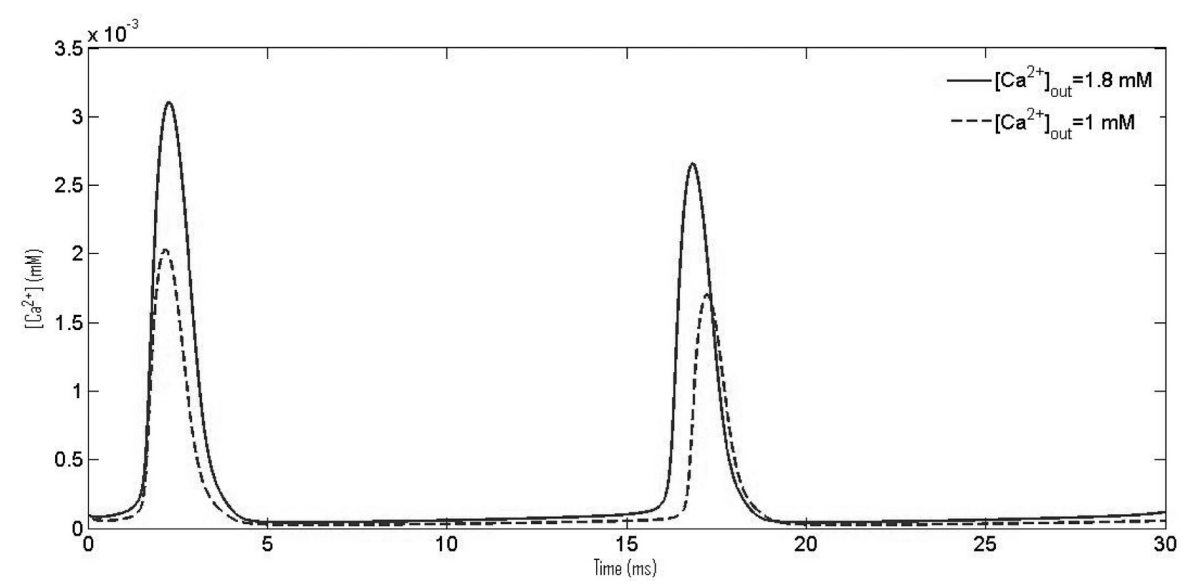

Figure $8-\mathrm{CaOs}$ with decreasing extracellular $\mathrm{Ca}^{2+}$ concentration, $\left[\mathrm{Ca}^{2+}\right]_{o}$.

centration resulted in an increase in frequency of $\mathrm{Ca}^{2+}$ oscillation. Although these findings are also pretty obvious as increasing $\left[\mathrm{K}^{+}\right]_{o}$ leads to an increase in reversal potential of $\mathrm{K}^{+}$ions and hence increases the frequency of action potential which in turn increases the frequency of $\mathrm{CaO}$. In Figure 10, the effect of decreasing $\left[\mathrm{Na}^{+}\right]_{o}$ concentration is shown. The curves are shown for $\left[\mathrm{Na}^{+}\right]_{o}=145 \mathrm{mM}$ (dark line) and $\left[\mathrm{Na}^{+}\right]_{o}=140 \mathrm{mM}$ (broken line), it is apparent from figure that decreasing $\left[\mathrm{Na}^{+}\right]_{o}$ results in an increase in amplitude of CaOs. As in the previous case changing $\left[\mathrm{Na}^{+}\right]_{o}$ concentration changes the reversal potential of $\mathrm{Na}^{+}$ion. But the observed change in $V_{N a}$ is minimal and 


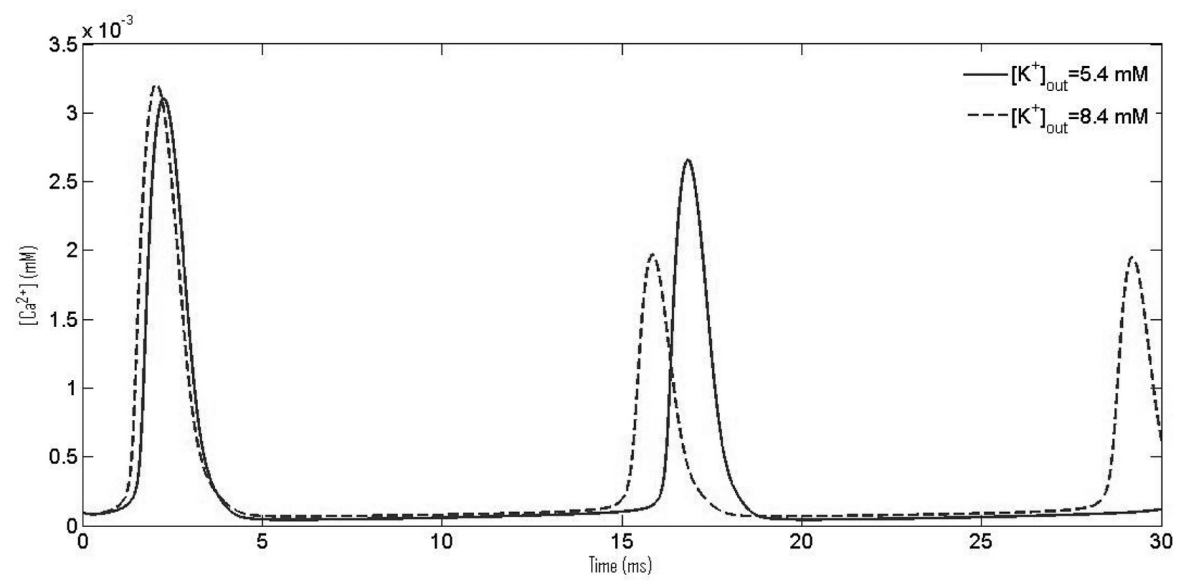

Figure $9-\mathrm{CaOs}$ with increasing extracellular $\mathrm{K}^{+}$concentration, $\left[\mathrm{K}^{+}\right]_{o}$.

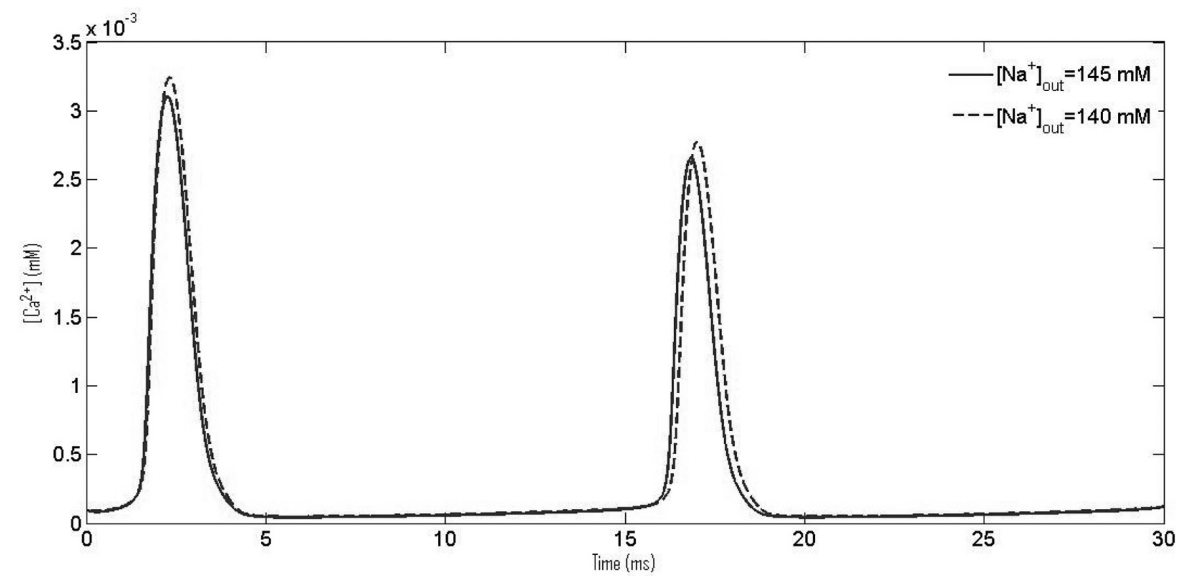

Figure $10-\mathrm{CaOs}$ with decreasing extracellular $\mathrm{Na}^{+}$concentration, $\left[\mathrm{Na}^{+}\right]_{o}$.

obviously does not affect amplitude of action potential. The reason behind the increase in amplitude and latency in $\mathrm{Ca}^{2+}$ oscillation is the change in $\mathrm{Na}^{+}$ion gradient. This gradient regulates the pumping rate of NCX exchanger decreasing the gradient means decreasing the pumping rate of NCX exchanger. Hence, affecting the net extrusion of $\mathrm{Ca}^{2+}$ ions via $\mathrm{NCX}$ exchanger; resulting in an increase in amplitude and latency of CaOs.

The results obtained in this paper are new and are subject to $\mathrm{CaO}$. The intent behind the present study was to investigate the effect of $\mathrm{Na}^{+} / \mathrm{K}^{+}$ATPase over $\mathrm{Ca}^{2+}$ oscillation influenced by the experimental results obtained by Matchkov et al. [27]. The results obtained by our simulations are quite convincing with 
biological facts. The obtained results also confirmed the hypothesis of Matchkov et al. [27] that interaction between $\mathrm{NCX}$ and $\mathrm{Na}^{+} / \mathrm{K}^{+}$ATPase modulates intercellular communication. It was observed that increasing $\mathrm{NaK}$ current decreases the frequency of $\mathrm{CaOs}$. The results obtained by previous investigators regarding $\mathrm{CaOs}$ have been mainly concerned with membrane potential, inositol triphosphate $\left(\mathrm{IP}_{3}\right)$ or ryanodine receptor $[6,28,29,10,11,12,13]$. None of the earlier investigators gave much emphasis over this interaction of NCX and sodium pump which in turn effects CaOs. Thus, in this article, we have looked into and demonstrated a novel mechanism which modulates frequency of $\mathrm{Ca}^{2+}$ oscillation. Here, we have proposed a mathematical model which can be used for problems related to similar cell processes. The results obtained in this paper give new and useful insight for neurologists to look into the paradigm of $\mathrm{CaOs}$ at a different perspective. Also, the results obtained are relevant to biomedical scientists for developing protocols for diagnosis and treatment of neurological disorders.

Acknowledgments. The author acknowledges fruitful discussions with Dr. Ronald J. Clarke, School of Chemistry, The University of Sydney, Australia for giving useful insights over the kinetics of $\mathrm{Na}^{+} / \mathrm{K}^{+}$ATPase.

\section{REFERENCES}

[1] A.C. Charles, C.C.G. Naus, D. Zhu, G.M. Kidder, E.R. Dirksen and M.J. Sanderson, Intercellular Calcium Signaling via Gap Junctions in Glioma Cells. The Journal of Cell Biology, 118 (1992), 195-201.

[2] A. Peskoff and G.A. Langer, Calcium Concentration and Movement in the Ventricular Cardiac Cell during an Excitation-Contraction Cycle. Biophys. J., 74 (1998), 153-174.

[3] J. Shuai, J.E. Pearson and I. Parker, Modeling $\mathrm{Ca}^{2+}$ Feedback on a Single Inositol 1,4,5-Trisphosphate Receptor and Its Modulation by $\mathrm{Ca}^{2+}$ Buffers. Biophys. J., 95 (2008), 3738-3752.

[4] O. Melien, L.S. Nilssen, O.F. Dajani, K.L. Sand, J-G Iversen, D.L Sandnes and T. Christoffersen, Ca2+-mediated activation of ERK in hepatocytes by norepinephrine and prostaglandin $F 2$ role of calmodulin and src kinases. BMC Cell Biol., 3 (2002).

[5] C.J. Dixon, J.F. Hall, T.E. Webb and M.R. Boarder, Regulation of Rat Hepatocyte Function by P2Y Receptors: Focus on Control of Glycogen Phosphorylase and 
Cyclic AMP by 2-Methylthioadenosine 5-Diphosphate. The Journal of Pharmacology and Experimental Therapeutics, 311 (2004), 334-341.

[6] M.S. Jafri, S.P. Vajda, S. Pasik and B. Gillo, A membrane model for cytosolic calcium oscillations: A study using Xenopus oocytes. Biophys. J., 63 (1992), 235-246.

[7] T.A. Fiacco and K.D. McCarthy, Intracellular Astrocyte Calcium Waves In Situ Increase the Frequency of Spontaneous AMPA Receptor Currents in CA1 Pyramidal Neurons. The Journal of Neuroscience, 24 (2004), 722-732.

[8] L. Sun, R. Hodeify, S. Haun, A. Charlesworth, A.M. MacNicol, S. Ponnappan, U. Ponnappan, C. Prigent and K. Machaca, Ca2+ Homeostasis Regulates Xenopus Oocyte Maturation. Biology of Reproduction, 78 (2008), 726-735.

[9] J. Keener and J. Sneyd, Mathematical Physiology. Springer, 8 (1998).

[10] A. Atri, J. Amundson, D. Clapham and J. Sneyd, A Single-Pool Model for Intracellular Calcium Oscillations and Waves in the Xenopus laevis Oocyte. Biophys. J., 65 (1993), 1727-1739.

[11] J. Wagner and J. Keizer, Effects of Rapid Buffers on Ca2+ Diffusion and Ca2+ Oscillations. Biophys. J., 67 (1994), 447-456.

[12] J.M.A.M. Kusters, M.M. Dernison, W.P.M. van Meerwijk, D.L. Ypey, A.P.R. Theuvenet and C.C.A.M. Gielen, Stabilizing Role of Calcium Store-Dependent Plasma Membrane Calcium Channels in Action-Potential Firing and Intracellular Calcium Oscillations. Biophys. J., 89 (2005), 3741-3756.

[13] H.S. Silva, A. Kapela and N.M. Tsoukias, A mathematical model of plasma membrane electrophysiology and calcium dynamics in vascular endothelial cells. Am. J. Physiol. Cell. Physiol., 293 (2007), C277-C293.

[14] M. Holmgren, J. Wagg, F. Bezanilla, R.F. Rakowski, P. De. Weer and D.C. Gadsby, Three distinct and sequential steps in the release of sodium ions by the $\mathrm{Na}+/ \mathrm{K}^{+}$ ATPase. Nature, 403 (2000), 898-901.

[15] A.L. Hodgkin and A.F. Huxley, A Quantitative Description of Membrane Current and its Application to Conduction and Excitation in Nerve. J. Physiol., 117 (1952), 500-544.

[16] C.H. Luo and Y. Rudy, A model of the ventricular cardiac action potential. Depolarization, repolarization, and their interaction. Circ. Res., 68(1991), 15011526.

[17] C.H. Luo and Y. Rudy, A dynamic model of the cardiac ventricular action potential. I. Simulations of ionic currents and concentration changes. Circ. Res., 74 (1994), 1071-1096. 
[18] C.H. Luo and Y. Rudy, A dynamic model of the cardiac ventricular action potential. II. After depolarizations, triggered activity, and potentiation. Circ. Res., 74 (1994), 1097-1113.

[19] T.R. Shannon, F. Wang, J. Puglisi, C. Weber and D.M. Bers, A Mathematical Treatment of Integrated Ca2+ Dynamics Within the Ventricular Myocyte. Biophys. J., 87 (2004), 3351-3371.

[20] G.L. Fain, Moleculer and cellular physiology of neurons. Harvard University Press (1999).

[21] D.L. Nelson and M.M. Cox, Lehninger Principles of Biochemistry. W.H. Freeman (2005).

[22] Y. Fujioka, K. Hiroe and S. Matsuoka, Regulation kinetics of Na+-Ca2+ exchange current in guinea-pig ventricular myocytes. J. Physiol., 529 (2000), 611-623.

[23] M.P. Blaustein and W.J. Lederer, Sodium / Calcium exchange: its physiological implications. Physiol. Rev., 79 (1999), 763-854.

[24] R.J. Clarke and D. J. Kane, Two Gears of Pumping by the Sodium Pump. Biophys. J., 93 (2007), 4187-4196.

[25] L.Y. Bourguignon, N. Iida, L. Sobrin and G.J. Bourguignon, Identification of an IP3 receptor in endothelial cells. J. Cell. Physiol., 159 (1994), 29-34.

[26] A. Miyakawa-Naito, P. Uhlen, M. Lal, O. Aizman, K. Mikoshiba, H. Brismar, S. Zelenin and A. Aperia, Cell Signaling Microdomain with Na,K-ATPase and Inositol 1,4,5-Trisphosphate Receptor Generates Calcium Oscillations. J. Bio. Chem., 278 (2003), 50355-50361.

[27] V.V. Matchkov, H. Gustafsson, A. Rahman, D.M. Boedtkjer, S. Gorintin, A.K. Hansen, E.V. Bouzinova, H.A. Praetorius, C. Aalkjaer and H. Nilsson, Interaction Between $\mathrm{Na}+/ \mathrm{K}+-$ Pump and $\mathrm{Na}+/ \mathrm{Ca} 2+-$ Exchanger Modulates Intercellular Communication. Circ. Res., 100 (2007), 1026-1035.

[28] G.W. De Young and J. Keizer, A single-pool inositol 1,4,5-trisphosphate-receptorbased model for agonist-stimulated oscillations in Ca2+ concentration. Proc. Natl. Acad. Sci. USA, 89 (1992), 9895-9899.

[29] J. Sneyd, S. Girard and D. Clapham, Calcium wave propagation by calciuminduced calcium release: an unusual excitable system. Bull. Math. Biol., 55 (1993), 315-344. 